\title{
Iniqüidades nas políticas de saúde: o caso da América Latina*
}

\author{
Iniquities in health policies: the Latin American case
}

Sonia Fleury

\begin{abstract}
Escola Brasileira de Administração Pública da Fundação Getúlio Vargas e Escola Nacional de Saúde Pública da Fundação Oswaldo Cruz - Rio de Janeiro - Brasil
\end{abstract}

\begin{abstract}
Sāo abordados quatro pontos sobre in|qüidades nas políticas de saúde: no primeiro deles, discute-se a crise econômica atravessada pela regiāo nas últimas décadas a problematiza-se o fato de a tendéncia à melhoria global do nivel de vida não tenha słdo profundamente afetada pela crise; no segundo ponto, discute-se as características do processo de desenvolvimento latino-americano, que tem sido marcado pelo aprofundamento das iniqüldades; no terceiro, apresenta-se uma análise do padrāo de proteção social na regiảo para, no último ponto, discutir dois modelos polares de reforma deste padrão.
\end{abstract}

Política de saúde. Desenvolvimento econômico. Qualidade de vida. Justiça social.

\section{Crises e Melhoramentos}

A América Latina (incluindo também o Caribe) é uma região com 443,3 milhões de habitantes (em 1991), com uma área de 20.507 milhares de $\mathrm{km}^{2}$, distribuídos em países com economias diversificadas**, sendo, no entanto, na média, uma região com uma renda per capita de US $\$ 2,390$, ou seja, onde predominam economias em desenvolvimento.

Depois de um prolongado ciclo expansionista, no qual a economia regional cresceu de forma persistente durante um período de 50 anos, desde a década de 80 a região vem sofrendo as consequiências do processo de endividamento, aceleraçāo inflacionária, recessāo e os efeitos das políticas de ajuste adotadas pelos governos locais (Tabela 1).
Nos últimos anos começam a ser sentidos os resultados das medidas de combate à inflaçăo e aumento da produtividade e competitividade da produção industrial, de tal forma que já se pode divisar, em alguns países, uma retomada do crescimento econômico (a variação acumulada do crescimento do produto interno bruto per capita entre 1981-1990 foi de - 8, 9 enquanto que entre 1991-1993 foi estimada em 4, 3).

Os indicadores de desenvolvimento social não são tão alentadores, já que se constata que, ainda hoje, um em cada cinco latino-americanos não dispőe de recursos suficientes para alimentar-se de forma adequada desde o ponto de vista nutricional (CEPAL'2, 1994), situaçāo que foi agravada pela recessão e também pelas medidas de ajuste estrutural da economia que levaram a

* Trabalho apresentado na II Conferencia Geral do FICOSSER - Federation for International Cooperation of Health Services and Systems Research Centers, Helsink, Finlandia.

** Segundo dados do Banco Mundial', no relatório de 1993 encontramos a seguinte classificaçäo de alguns dos paises da regiáo, segundo sua renda (PND) per capita:

Baixa renda ( $\$$ \$ $\$ 35$ ou menos): Haiti, Nicaragua, Honduras

Renda média (' $\$ \$ 636$ a 7.909 )

Renda média "ixa:Boltvia, Guatemala, República Dominicana, Equador, Peru, El Salvador, Colómbia, Paraguai, Jamaica, Costa Rica, Pa amá. Chile

Renda média a y: Venezuela, Argentina, Uruguai, Brasil, Méxica, Trinidad e Tobago.

Separatas/Rep. uts: Sonia Fleury - Fundą̧óo Oswaldo Cruz/Presidência - Av. Brasil, 4365 - 2J040-360 - Rio de Janeiro, RJ Brsasit - Fax: 21) 541.9402

Recebido em 19.9.1994. Aprovado em 12.4.1995. 
Tabela 1 - América Latina - Indicadores básicos.

Populaçăo - milhões, meados 1991: 445,3 t

Area - milhares $\mathrm{Km}^{2}-20.507 \mathrm{t}$

PNB per capita - 1991 - US\$ 2,390 w

PNB - taxa média crescimento anual \% - 1980-91: -0,3 w

Inflação - taxa média anual \%: $\quad$ 1970-80: 3,1 w

1980-91: $208,2 \mathrm{w}$

Divida externa, como \% do PNB: $1980: 35,1 \mathrm{w}$

1991: $41,3 \mathrm{w}$

PIB - variaçăo acumulada:

1981-90: $-8,9$

1991-93: 4,3

Urbanização - população rural:* 1950: $60 \%$

1990: $30 \%$

Fonte: Banco Mundial', (1993)

* Fonte - CEPAL ${ }^{2}, 1994$

Convenções: $\mathrm{t}$ - total; $w$ - média ponderada

Tabela 2 - Indices de pobreza e renda per capita em diferentes regiōes do mundo

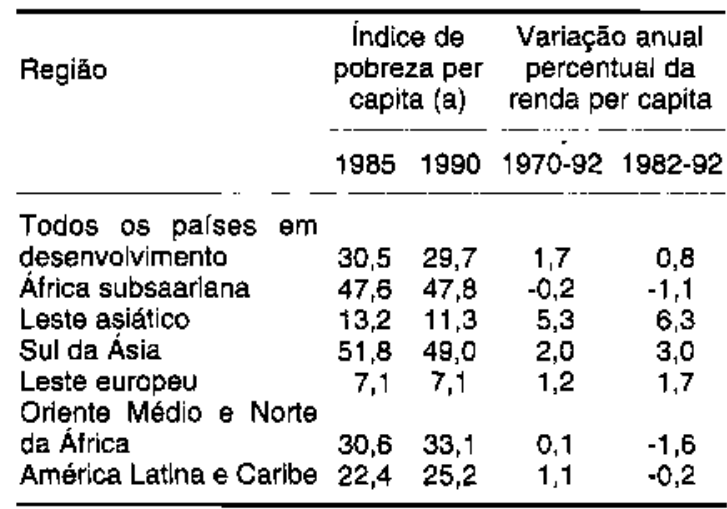

Fonte: Banco Mundial ${ }^{7}$ (1993)

Nota: Os dados regionais sobre a variaçào anual da renda per capita referem-se a médias näo-ponderadas de palses. As regiôes referidas na tabela são aquelas definidas nos Indicadores do Desenvolvimento Mundial, exceto no caso do Leste europeu, que inclui Albânia, Bulgária, Hungria, Polónia, Roménia, a ex-República Socialista Federativa da lugoslávia e a exTchecoslováquia.

Ainda não se dispóe de dados desagregados para estes dois últimos paises.

a) Parcela estimada da populaçāo que consome menos de US\$ 32 mensais por pessoa, a preços ajustados pela raridade do poder de compra de 1985.

reduçāo do nível de emprego e das renumeraçōes (Tabela 2).

No entanto, a crise da última década não chegou a inverter as tendências positivas de longo prazo, apenas diminuindo o ritmo das melhorias que se refletem em indicadores sociais, tais como: cobertura do sistema educacional, acesso à água e esgoto, reduçāo das taxas de mortalidade infantil (mais de $50 \%$ entre 1950 e 1990), aumento da esperança de vida ao nascer (passando de 52 anos entre 1950-55 para 67 anos no período de 1985-1990).
$\hat{E}$ ainda necessário ter em conta as profundas transformaçōes econômicas e sociais que a regiāo vem atravessando nas últimas décadas, com um intenso processo de urbanização e migração (em 1950 quase $60 \%$ dos habitantes residia em áreas rurais enquanto em 1990 esse número foi reduzido para $30 \%$ ), reduçāo das taxas de fecundidade (em 1950 a média era de 6 filhos por mulher enquanto entre 1985-1990 essa média caiu para 3,4), alteraçóes da estrutura etária com o aumento do número de idosos compensando a redução da populaçāo infantil.

Todas essas mudanças provocaram alteração do perfil epidemiológico regional, onđe predominavam as causas de morte por doenças transmissíveis com a persistência de doenças endêmicas. $O$ quadro atual tornou-se complexo, já que, sem ałcançar solução para as doenças típicas do subdesenvolvimento, passaram a ter importância crescente as enfermidades próprias da idade adulta como as cardiovasculares (primeira causa de morte) e o câncer (segunda causa de morte) além das causas externas como os acidentes e a violência (terceira causa de morte).

Comparando as condições de saúde na região com o resto do mundo (Tabela 3 ) verifica-se que a mortalidade infantil registrada na América Latina (44 por mil nascidos vivos) é muito mais alta do que a dos países ricos da "Organización de Cooperación y Desarrollo Económico" (OCDE) (8 por 1,000 ), embora seja inferior à média mundial (53 por 1.000 nascidos vivos) e algumas regiões com renda equivalente. $O$ mesmo padrão apresenta-se em relaçāo à esperança de vida ao nascer na regiāo (68 anos na América Latina, 77 anos nos membros da OCDE e 66 anos na média mundial).

Já a comparação em termos dos recursos econômicos, destinado ao setor saúde, demostra que a regiāo encontra-se em situaçāo muito desfavorável, destinando apenas US\$ 121 per capita para a saúde, enquanto que a média mundial US\$ 323. Estima-se que a participação do setor saúde no PIB da região seja de 5\%, sendo muito menor que a média mundial de $8 \%$. Já o gasto público em saúde representa $2,2 \%$ do PIB, o que corresponde a menos da metade da média mundial $(4,9 \%$ do PIB) (Tabela 4).

Em relação ao financiamento da saúde observa-se que na última décađa houve uma redução do financiamento público com o concomitante aumento do gasto privado das familias, empresas e ONG (Organização não governamental). O crescimento das ONG's no financiamento da saúde na região assume proporçōes volumosas, tendo cana- 
Tabela 3 - Comparação entre América Latina e Caribe e demais regiōes do mundo: indicadores de saúde e desenvolvimento.

\begin{tabular}{|c|c|c|c|c|}
\hline Grupos de paises por nível de renda & $\begin{array}{c}\text { Taxa de mortalidade } \\
\text { infantil (a) }\end{array}$ & $\begin{array}{c}\text { Mortalidade } \\
\text { geral (b) }\end{array}$ & $\begin{array}{c}\text { Esperança de vida } \\
\text { ao nascer (c) }\end{array}$ & $\begin{array}{l}\text { Produto per } \\
\text { capita (d) }\end{array}$ \\
\hline $\begin{array}{l}\text { Países de renda baixa ou média } \\
\text { Paises de renda baixa } \\
\text { Paises de renda média } \\
\text { Gravemente endividados } \\
\text { Paises de renda alta } \\
\text { Miembros da OCDE } \\
\text { Paises de renda médla-baixa }\end{array}$ & $\begin{array}{r}61 \\
71 \\
38 \\
48 \\
8 \\
8\end{array}$ & $\begin{array}{r}10 \\
10 \\
8 \\
8 \\
9 \\
9\end{array}$ & $\begin{array}{l}64 \\
62 \\
68 \\
67 \\
77 \\
77\end{array}$ & $\begin{array}{r}1.010 \\
350 \\
2.480 \\
2.350 \\
21.050 \\
21.530\end{array}$ \\
\hline $\begin{array}{l}\text { África ao sul do Saara } \\
\text { Ásia Oriental e do Pacífico } \\
\text { Asia meridional } \\
\text { Europa e Ásia Central } \\
\text { América Latina e Caribe } \\
\text { Oriente Médio e Norte da África }\end{array}$ & $\begin{array}{r}104 \\
42 \\
92 \\
26 \\
44 \\
60\end{array}$ & $\begin{array}{r}16 \\
7 \\
11 \\
10 \\
7 \\
8\end{array}$ & $\begin{array}{l}51 \\
68 \\
59 \\
70 \\
68 \\
64\end{array}$ & $\begin{array}{r}350 \\
650 \\
320 \\
2.670 \\
2.390 \\
1.940\end{array}$ \\
\hline Todo o mundo & 53 & 9 & 66 & 4.010 \\
\hline
\end{tabular}

Fonte: Banco Mundial? (1993),

(a) Taixa de mortalidade infantil de 0 a 1 año por 1.000 nascidos vivos.

(b) Mortalidade geral por 1.000 habitantes.

(c) Esperança de vida ao nascer, expressa em anos.

(d) Produto per capita, dólares de 1991.

lizado entre 1980 e 1989 um total de US\$ 6 bi1hões, sendo que sua participação, nos países mais pobres, chega a ser similar a ou superior à dos govemos locais.

A oferta de serviços apresentou uma tendência a deterioração dos serviços públicos, como consequiência da redução do gasto público no setor, com aumento da defasagem tecnologica entre os serviços hospitalares públicos e privados, e perda da eficiência e eficácia da atenção à saúde no setor público. Como resultado houve aumento da oferta de serviços pelo setor privado, que teve um cresci- mento acentuado nos anos regentes, especialmente na modalidade de seguro saúde tanto em termos de afiliações quanto à oferta de camas hospitalares.

Em resumo, podemos observar que a América Latina é uma região com perfil de países em desenvolvimento que foram fortemente afetados, nas áltimas décadas, pela crise econômica. Mesmo assim, enquanto os indicadores de renda assinalam um aumento da pobreza na região, os indicadores sociais mantem, em ritmo mais suave, a tendência à melhoria das condiçốes gerais de saúde. Em outras palavras, à nomeada década per-

Tabela 4 - Comparação dos gastos com saúde em diferentes regiōes do mundo.

\begin{tabular}{|c|c|c|c|c|c|c|c|}
\hline Região demográfica & $\begin{array}{c}\text { Percentual } \\
\text { da } \\
\text { populaçảo } \\
\text { mundial }\end{array}$ & $\begin{array}{c}\text { Gastos } \\
\text { totais com } \\
\text { saúde } \\
\text { (bilhöes } \\
\text { de US\$) }\end{array}$ & $\begin{array}{l}\text { Gastos } \\
\text { totais com } \\
\text { saúde como } \\
\% \text { do total } \\
\text { mundial }\end{array}$ & $\begin{array}{l}\text { Gastos } \\
\text { públicos } \\
\text { com saúde } \\
\text { como \% do } \\
\text { total regional }\end{array}$ & $\begin{array}{l}\text { Percentual } \\
\text { (\%) do } \\
\text { PNB gasto } \\
\text { em saúde }\end{array}$ & $\begin{array}{l}\text { Gasto per } \\
\text { capita com } \\
\text { saúde } \\
\text { (US\$) }\end{array}$ & $\begin{array}{c}\text { Coeficiente } \\
\text { de gastos } \\
\text { per capita } \\
\text { (AS-1) }\end{array}$ \\
\hline $\begin{array}{l}\text { Economias de Mercado } \\
\text { Consolidadas }\end{array}$ & 15 & 1.483 & 87 & 60 & 9,2 & 1.860 & 78,9 \\
\hline $\begin{array}{l}\text { Ex-economias } \\
\text { Socialistas Européias }\end{array}$ & 7 & 49 & 3 & 71 & 3,6 & 142 & 6.0 \\
\hline América Latina & 8 & 47 & 3 & 60 & 4,0 & 105 & 4,5 \\
\hline Oriente Médio Crescente & 10 & 39 & 2 & 58 & 4,1 & 77 & 3,3 \\
\hline Outros da Ásia e lihas & 13 & 42 & 2 & 39 & 4,5 & 61 & 2,6 \\
\hline ĺndia & 16 & 18 & 1 & 22 & 6,0 & 21 & 0,9 \\
\hline China & 22 & 13 & 1 & 59 & 3,5 & 11 & 0,5 \\
\hline África subsaariana & 10 & 12 & 1 & 55 & 4,5 & 24 & 1,0 \\
\hline $\begin{array}{l}\text { Paises em desenvolvi- } \\
\text { mento demográfico }\end{array}$ & 78 & 170 & 10 & 50 & 4,7 & 41 & 1,7 \\
\hline Mundo & 100 & 1.702 & 100 & 60 & 8,0 & 329 & 13,7 \\
\hline
\end{tabular}

AS: Africa Subsaariana

Fonte: Banco Mundial?, (1993) 
dida (já são quase duas) na área econômica não correspondeu a mesma perda em termos de desenvolvimento social.

Tal fenômeno deve ser atribuido tanto à estrutura de serviços sociais que havia sido instalada em vários países durante o período de expansāo econômica, quanto a outras características sociodemográficas associadas ao acelerado ritmo de urbanização.

Finalmente, ao lado das alterações no perfil epidemiológico e no padrão da demanda, observase também, como resultado da crise econômica, o conjunto de mudanças no padrão da oferta de serviços de saúde, em direção a uma maior participação do setor privado (filantrópico e de mercado), tanto no financiamento quanto na oferta de serviços, enquanto há uma reduçāo e deterioraçāo da participação do setor público.

\section{Aprofundando as Iniqüidades}

A economia política latino-americana, desenvolvida na CEPAL no final dos anos 40 , trouxe contibuiçāo original ao analisar o processo de desenvolvimento e industrialização das economias periféricas a partir do conceito de heterogeneidade estrutural. Em breves linhas, partia-se da análise da distribuição desigual dos frutos do progresso técnico a favor dos países centrais, com a crescente deterioração dos termos de troca, em consequiência da heterogeneidade persistente da estrutura produtiva nos países da periferia. Esta industrialização dependente levaria à marginalização crescente de setores da população urbana, alijando-se dos benefícios do progresso, de tal forma a alimentar um processo político singular, no qual os conflitos distributivos perdem sua aparência de conflitos para serem transformados em pleitos junto ao Estado.

O crescimento econômico sustendado durante 5 décadas demonstrou que nāo existe uma relaçāo imediata entre crescimento $\mathrm{e}$ desenvolvimento social. A experiência histórica da América Latina neste século fundamenta a tese segundo a qual o crescimento econômico, embora seja condição necessária para o combate à pobreza e a redução das iniqüidades*, além de não ser suficiente, alcança maior efetividade quando se faz acompanhar de uma melhoria na distribuição da renda.

\footnotetext{
* Adota-se aqui a definiça de Whitehea (1990) para iniquidade em saude, entendida como sendo as diferenças sistemáticas que são desnecessárias e evitoveis, ademais de injustas.
}

Uma segunda tese pode ser tambem confirmada pela experiência latino-americana, qual seja, que o gasto social também pode contribuir para a diminuiçāo da pobreza, tornado mais accessíveis à população um conjunto de seviços básicos, tendo como vantagem sua autonomia relativa tanto do nível como do ritmo de expansão do produto (Tokman', 1991).

Como vimos anteriormente, a manutenção da melhoria dos indicadores sociais durante o período de crise econômica é parcialmente atribuída à existência de uma rede de serviços sociais que pode tornar disponíveis à populaçāo mais carente certas tecnologias (como vacinas e a reidrataçāo oral) e conhecimentos (por exemplo, a higiene e a importância do aleitamento materno), reduzindo os efeitos da renda sobre os indicadores sociais.

A tentativa de apreender o grau de equiidade/iniqüidade social tem levado ao desenvolvimento de um conjunto de indicadores mais sensíveis, que permitem desvendar como se distribuem diferencialmente os benefícios do progresso. Assim, hoje, já se pode dispor de indicadores de probreza tradicionais como a renda sendo cotejados com um indicador de pobreza, segundo necessidades básicas (falta de acesso aos bens públicos como serviços básicos de saúde, educação, moradia), desenvolvido pelo PNUD (Programa das Naçôes Unidas para o Desenvolvimento ${ }^{4}$ ). Se adotado este segundo critério estima-se que cerca de $18 \%$ da população latinoamericana que não seria considerada pobre segundo a renda, o seria por insatisfação de suas necessidades essenciais (Tokmams, 1991).

A necessidade de medir o impacto global da doença (IGD) levou o Banco Mundial e a Organização Mundial de Saúde ao desenvolvimento de um indicador de anos de vida ajustados por incapacidade ( $\left(\mathrm{VVAI}^{\prime}\right.$ ), somando as perdas por morte prematura com a perda da vida saudável causada por incapacidade (Tabela 5).

Tais indicadores de iniqüidade na saúde são fundamentais para orientar os "policy-makers"em relação ao estabelecimento de metas de eqüidade, tais como as expressas nos valores das brechas de mortalidade reduzíveis, ou seja, aquilo que $\epsilon$ considerado ser possível superar a partir das condiçōes socioeconômicas do país (CEPAL', 1994).

Os cenários projetados para a economia regional, em estudos do Banco Mundial' e do PNUD', apesar das diferenças, indicam tendência comum na direção do crescimento da economia regional, superando a recessão da década passada. No entanto, os estudos e projeções realizados pelo PREALC (Programa Regional de Emprego para a América 
Tabela 5 - Distribuição da perda de AVAL, por causa e regiẫo demográfica, 1990.

\begin{tabular}{|c|c|c|c|c|c|c|c|c|c|}
\hline Causa & Mundo & $\begin{array}{l}\text { Affica } \\
\text { sub- } \\
\text { saariana }\end{array}$ & Índia & China & $\begin{array}{l}\text { Outros } \\
\text { da Asia } \\
\theta \text { llhas }\end{array}$ & $\begin{array}{c}\text { América } \\
\text { Latina e } \\
\text { Caribe }\end{array}$ & $\begin{array}{l}\text { Oriente } \\
\text { Médio } \\
\text { Crescente }\end{array}$ & $\begin{array}{c}\text { Ex-economias } \\
\text { socialistas } \\
\text { européias }\end{array}$ & $\begin{array}{l}\text { Economias } \\
\text { de mercado } \\
\text { consolldadas }\end{array}$ \\
\hline Populaçāo (milhōes) & 5.267 & 510 & 850 & 1.134 & 683 & 444 & 503 & 346 & 798 \\
\hline Doenças transmissiveis & 45,8 & 71,3 & 50,5 & 25,3 & 48,5 & 42,2 & 51,0 & 8,6 & 9,7 \\
\hline Tuberculose & 3,4 & 4,7 & 3,7 & 2,9 & 5,1 & 2,5 & 2,8 & 0,6 & 0,2 \\
\hline DST e HIV & 3,8 & 8,8 & 2,7 & 1,7 & 1,5 & 6,6 & 0,7 & 1,2 & 3,4 \\
\hline Dlarréia & 7,3 & 10,4 & 9,6 & 2,1 & 8,3 & 5,7 & 10.7 & 0,4 & 0,3 \\
\hline Infeccöes infantis imunizáveis & 5,0 & 9,6 & 8,7 & 0,9 & 4,5 & 1,6 & 6.0 & 0,1 & 0,1 \\
\hline Malária & 2,6 & 10,8 & 0,3 & * & 1,4 & 0,4 & 0,2 & * & 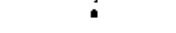 \\
\hline Vermlnoses & 1,8 & 1,8 & 0,8 & 3,4 & 3,4 & 2,5 & 0,4 & * & n \\
\hline Infeccöes respiratórias & 9,0 & 10,8 & 10,9 & 6,4 & 11,1 & 6,2 & 11,5 & 2,6 & 2,6 \\
\hline Causas matemas & 2,2 & 2,7 & 2,7 & 1,2 & 2,5 & 1,7 & 2,9 & 0,8 & 0,6 \\
\hline Causas perinatais & 7,3 & 7,1 & 9,1 & 5,2 & 7,4 & 9,1 & 10,9 & 2,4 & 2,2 \\
\hline Outras & 3,5 & 4,6 & 4,0 & 1,4 & 3,3 & 5,8 & 4,9 & 0,6 & 0,5 \\
\hline Doenças nạo-transmissiveis & 42,2 & 19,4 & 40,4 & 58,0 & 40,1 & 42,8 & 36,0 & 74,8 & 78,4 \\
\hline Câncer & 5,8 & 1,5 & 4,1 & 9,2 & 4,4 & 5,2 & 3,4 & 14,8 & 19,1 \\
\hline Deficiências nutricionais & 3,9 & 2,8 & 6,2 & 3,3 & 4,6 & 4,6 & 3,7 & 1,4 & 1,7 \\
\hline Doença neuropsiquilátrica & 6,8 & 3,3 & 6,1 & 8,0 & 7,0 & 8,0 & 5,6 & 11,1 & 15,0 \\
\hline Doença cerebrovascular & 3,2 & 1,5 & 2,1 & 6,3 & 2,1 & 2,6 & 2,4 & 8,9 & 5,3 \\
\hline Isquemia cardiaca & 3,1 & 0,4 & 2,8 & 2,1 & 3,5 & 2,7 & 1,8 & 13,7 & 10,0 \\
\hline Obstrução puimonar & 1,3 & 0,2 & 0,6 & 5,5 & 0,5 & 0,7 & 0,5 & 1,6 & 1,7 \\
\hline Outras & 18,0 & 9,7 & 18,5 & 23,6 & 17,9 & 19,1 & 18,7 & 23,4 & 25,6 \\
\hline Traumas & 11,9 & 9,3 & 9,1 & 16,7 & 11,3 & 15,0 & 13,0 & 16,6 & 11,9 \\
\hline Automobilísticos & 2,3 & 1,3 & 1,1 & 2,3 & 2,3 & 5,7 & 3,3 & 3,7 & 3,5 \\
\hline Intencionais & 3,7 & 4,2 & 1,2 & 5,1 & 3,2 & 4,3 & 5,2 & 4,8 & 4,0 \\
\hline Outros & 5.9 & 3,9 & 6,8 & 9,3 & 5,8 & 5,0 & 4,6 & 8,1 & 4,3 \\
\hline Total & 100,0 & 100,0 & 100,0 & 100,0 & 100,0 & 100,0 & 100,0 & 100,0 & 100,0 \\
\hline Milhöes de AVAL & 1.382 & 293 & 292 & 201 & 177 & 103 & 144 & 58 & 94 \\
\hline $\begin{array}{l}\text { Equivalente em obitos Infan- } \\
\text { tis (milhöes) }\end{array}$ & 42,0 & 9,0 & 9,0 & 6,2 & 5,5 & 3,2 & 4,4 & 1,8 & 2,9 \\
\hline AVAL por mil habitantes & 259 & 575 & 344 & 178 & 260 & 233 & 286 & 168 & 117 \\
\hline
\end{tabular}

* Menos de $0,05 \%$.

AVAL: anos de vida ajustados por incapacidade.

DST: doença sexualmente tranmissivel.

HIV: virus da imunodeficiéncia humana.

Fonte: Banco Mundial? (1993).

Latina e Caribe) (apud Tokmans, 1991) sobre emprego indicam tendências no sentido de aumento da diferenciaçāo social, como: o problema da pobreza será crescentemente um fenômeno urbano e aumentará a participação do setor informal na força de trabalho urbana com a queda da renda média, ampliando a dispersāo dos salários com a expansāo dos salários mais altos nos setores de maior produtividade. Em outros termos, os estudos indicam um cenário onde a melhoria das condições gerais de pobreza vai se fazer acompanhar por uma redução na eqüidade (Tokman ${ }^{3}, 1991$ ).

Há algumas razōes para explicar essas tendências perversas da retomada do crescimento econômico na região. A modernização atual da estrutura produtiva com vistas à incorporação tecnologica e aumento da competitividade é decorrência das transformações da economia internacional a partir da introduçăo do novo paradigma de organizaçăo industrial e tecnologica liderado pelo complexo eletrônico. A vinculação das economias em desenvolvimento a essa dinâmica internacional tem dado origem ao fenômeno de "integraçāo transnacional e desintegraçāo nacional", dando lugar a uma segmentação tripartite, ainda que estreitamente inter-relacionada, da economia e da sociedade: de um lado a economia de competiçāo oligoṕlica dos grandes gigantes internacionais, de outro a economia de mercado tradicional dos produtores médios e pequenos, e, agregado a esta, uma vasta massa da economia marginal e informal (Sunkel ${ }^{4}, 1987$ ).

$\mathrm{Na}$ análise de Lechner ${ }^{1}$ (1990), tal situação caracteriza uma nova "heterogeneidade estrutural", na medida em que as distâncias sociais não só se aprofundaram quantitativamente como foram modificados qualitativamente, dando lugar a uma ordem social segmentada. $O$ aprofundamento da iniqüiidade, a "urbanizaçāo da miséria", a falência do Estado para cumprir suas funções mínimas (econômicas: segurança, moeda, tributaçāo; e sociais: educaçāo, saúde, habitaçāo), levaram a América Latina a uma situação sem precendentes, 
que se expressa na decomposição do tecido social nas grandes metrópoles. Os dados sobre a crescente violência, criminalidade e suas ligações com o aumento do tráfico de drogas apontam para uma realidade explosiva.

Se a dinâmica de mercado exclui cerca de um terço da população latino-americana da produçăo formal e do consumo mínimo - e as novas bases para retomada do crescimento econômico não parecem indicar a possibilidade de equacionamento desta questão - a sobrevivência desta parcela da população relegada pelo modelo econômico está, cada vez mais, na dependência da atuaçāo do Estado. Enquanto para alguns o Estado deveria atuar na área de saúde com vistas apenas ao combate à pobreza, em programas específicos e focalizados, outros compreendem a importância da dimensão econômica do setor saúde na região (que representa cerca de $5 \%$ do PIB e emprega $5 \%$ da população economicamente ativa) e formulam uma proposta na qual o setor público tem lugar estratégico no esforço para lograr a transformação produtiva com equiidade social.

Neste sentido, foi analisado, no proximo ponto, o padrão de proteçāo social latino-americano e as atuais tendências de reforma.

\section{- Padrão de Proteção Social Latino- Americano: Cooptação e Exclusão*}

Na América Latina pode-se encontrar alguns dos mais antigos complexos e institucionalizados sistemas de proteção social, que tiveram início na virada do século em países como Argentina, Uruguai, Chile e Brasil.

Conformou-se nesses países um sistema de Seguridade Social caracterizado pela sua fragmentação, com a existência de múltiplas instituições e regimes de contribuição e benefícios, a depender do poder de barganha de cada categoria de trabalhador ao qual se aplicava. A cooptação política das fraçōes mais organizadas e estratégicas da classe trabalhadora, através dos aparelhos de políticas sociais, transformava os cidadãos em clientes das estruturas burocráticas do Estado. A dimensāo juríđica da cidadania, enquanto igual-

\footnotetext{
* A análise do padrão de proteção social na regiāo tomará por base os sistemas de Seguridade Social que abarcam as polticas de previdência, saúde e assistência. Embora existam serviços serviços de saúde pública que não pertençam a Seguridade Social, e sim ao Ministério da Saúde, a tendência mais marcante é que a Seguridade dê conta da maior parte da atenção médica curativa na regiāo.
}

dade formal diante do Estado, foi transmutada em desigualdade política na concessão diferencial de privilégios cumulativos a alguns setores da classe trabalhadora, enquanto os grupos mais necessitados eram excluídos da proteção social.

As tentativas de reformaçāo do sistema de Seguridade Social, na direção de uma maior uniformidade, unificação e universalização foram frustadas em muitos pontos, em um processo de marchas e contra-marchas em que se buscava modernizar as estruturas administrativas e viabilizar sua gestão mais racional, tendo, no entanto, como limite, o próprio tecido político em torno da proteção social.

A complexidade da estrutura política, a insatisfação das expectativas geradas por este processo, 0 acirramento das contradições entre cooptação e controle, tornaram difícil a possibilidade de compatibilizar as demandas emergentes no curso do processo de industrialização com a lógica política que presidiu a montagem dos sistemas de Seguridade Social. Por isto, a expansāo e maturação desses sistemas manifestaram como crise, insolúvel nos marcos da sua estrutura original.

Entre os anos 60 e 70 os governos militares que tomaram o poder nos países do Cone Sul, da América Latina, buscaram reformar o sistemas de proteção social na Argentina, Brasil, Chile e Uruguai. As reformas levadas a cabo no regime autoritário-burocrático caracterizam-se pela tentativa de exclusăo do processo decisório das políticas sociais daquelas forças mobilizadas durante o período populista, de forma a eliminar o jogo político da barganha e pressão exercidas pelos trabalhadores.

A despolitização da questão social correspondeu, ao mesmo tempo, ao fortalecimento das estruturas burocráticas, em um contexto de supressão da cidadania política $e$ eliminaçāo dos canais de representação e organização das demandas sociais.

A substituição dos mecanismos de representação corporativos por canais burocráticos teve um sentido claro de privilegiamento dos interesses dos produtores privados de serviços, especialmente no caso da atenção à saúde, como se evidência na redução dos serviços públicos, na deterioração da rede existente e na introdução de diferentes modalidades de privatização da lógica estatal.

A redução do gasto público social marcou todos os governos nesse período, sendo que as medidas de ampliação da proteção social, quando ocorreram, foram custeadas por recursos parafiscais, quase sempre advindos do aumento de contribuiçōes sobre a folha de salários. 
A década de 80 na América Latina foi caracterizada por dois fenômenos que atuaram simultânea e contraditoriamente sobre o sistema de proteção social. Por um lado, a crise econômica e o endividamento externo afetaram profundamente a economia regional. reduzindo a capacidade financeira do Estado. Os custos sociais das medidas de ajuste também foram enormes, com aumento do desemprego e diminuição da renda.

Por outro lado, muitos países iniciaram nesse período seu processo de transiçào à democracia. trazendo, no bojo da luta pela restauração do Estado de Direito, demandas sociais longamente reprimidas.

Esses fatores, embora de forma divergentes, confluíram para a formulação de modelos distintos de reforma da proteção social, tendo como princípios norteadores a busca da eficiência em um caso e o aumento da justiça social em outro. Neste sentido. podemos encontrar dois casos paradigmáticos, o do Brasil e do Chile, que configuraram modelos distintos de reformulação da proteção social. polarizando o debate e as forças políticas nos demais países da regiào.

\section{Chile: Reforma Liberal-Produtivista}

A reforma chilena consistiu na transposição dos fundos de pensão e de saúde para instituições privadas criadas para este fim. de forma que o Estado ficou responsável apenas pela parcela da população mais pobre. que não alcançava comprar um seguro privado no mercado.

Embora seja um modelo de inspiração liberal. trata-se de um seguro compulsório que é também regulamentado e fiscalizado pelo poder público. Com rompimento do modelo triportate anterior. o financiamento da proteção social passou a ser responsabilidade exclusiva do trabalhador, no caso de sua filiação a um seguro privado, ou do poder público na cobertura de medicina preventiva e atenção integral para a população pobre.

Essa reforma, pela primeira vez quebrou a espinha dorsal do sistema de seguridade montado pelos governos populistas, alterou a lógica corporativa solidária em direção a um parâmetro produtivista, no qual privilegia-se a proteção àquela parcela da populaçâo trabalhadora que está inserida nos setores mais dinâmicos da economia, enquanto aqueles que se vinculam aos setores mais atrasados e/ou no mercado informal passam a ter um tratamento público diferencial.

Para se ter una noção dos efeitos desta política que estratifica a proteção social em função da lógica econômica podemos tomar os dados sobre o gasto em saúde como exemplo. Em 1991, os seguros privados atingiram uma cobertura de cerca de $19 \%$ da população e absorveram $50 \%$ do gasto total em saúde. Supõem-se que os outros $50 \%$ deveriam dar conta da atenção primária para toda a população e da cobertura total dos restantes $80 \%$, onde se localizam os grupos mais pobres. alếm daqueles que foram progressivamente excluídos do mercado da saúde. como os idosos e os doentes crônicos.

O sistema público de saúde foi descentralizado e orientado para a focalização em relação aos grupos mais vulneráveis - por exemplo, maternoinfantil-ainda que tenha que cobrir a maioria da população com reduzidos recursos.

Em resumo, a reforma chilena aumentou o grau de iniquiidade do sistema de proteção social, assumindo que a política social deve ter um formato que corresponda à segmentação existente na esfera econômica.

\section{Brasil: Reforma Universal Publicista}

No Brasil, organizou-se, desde os anos 70 , um forte movimento social no campo da saúde. reunindo intelectuais, parlamentares, burocratas e usuários, em torno das lutas pela democratização do país e, especifica, pela democratização do campo da saúde, reivindicando a melhoria da qualidade de vida da população e a universalização do acesso ao sistema de saúde.

Tal proposta foi inserida na Constituição de 1988 , onde a saúde ficou inscrita como direito da cidadania e dever do Estado, devendo os serviços de saúde organizar-se em um sistema único, público, universal, de atençāo integral, descentralizado e democraticamente gerido com a participação da sociedade.

A força política alcançada pelo "movimento sanitário" foi suficiente para realizar as mudanças legais e institucionais referentes à unificação dos serviços públicos do Ministério da Saúde com os da Seguridade Social, descentralização das competências e recursos e universalização virtual da cobertura. No entanto. não foi capaz de alterar a realidade da oferta de insumos e serviços cujas características são: a produção de fármacos, equipamentos hospitalares e outros insumos é basicamente realizada por empresas transnacionais, sendo que o govemo não alcança controlar nem a oferta nem os preços desses produtos; os leitos hospitalares são predominantemente ofertados pelo setor privado $(77,1 \%)$; a distribuição dos recursos hospitalares e dos recur- 
sos humanos é altamente concentrada nas regiões urbanas mais ricas do país.

A persistência desses fatores determinou a inviabilização, na prática, do principio básico que garantia a eqüidade no acesso a toda a população brasileira. Além disso, o fato mais crucial no impedimento do cumprimento das determinaçōes legais foi a redução brutal do gasto público em saúde: enquanto em 1989 o gasto per capita em saúde foi de US\$ 81.43 em 1991 foi de apenas US\$ 54.33.

Como consequiência da redução do gasto público em saúde o que se observou foi um processo de auto-exclusão de produtores de serviços e usuários que, por apresentarem condições mais vantajosas de sobrevivência no mercado, retiraram-se do Sistema Único de Saúde. Ao fim de pouco mais de 5 anos o que se pode observar é uma perversão da proposta original de um sistema público, igualitário e universalizado em saúde. $O$ sistema públi$\mathrm{co}$, em péssimas condiçōes de funcionamento, acabou ficando apenas com a atençāo destinada à parcela mais pobre da população, que não conseguiu, através do empregador privado ou do próprio Estado (cujas empresas garantem planos de saúde para seus funcionários) ter acesso ao mercado privado de saúde.

\section{Referências Blbllográficas}

1. LECHNER, N. A modernidade e a modernização são compatíveis? O desafio da democracia latino-americana lua Nova (21), 1990.

2. ORGANIZACIÓN PANAMERICANA DE LA SALLD. Salud, equidad y transformación productiva en América Latina y el Caribe. Washington, CEPAL/OPS, 1994. (Série Documentos Reproducidos, $n^{\circ} 31$ ).

3. PROGRAMA DAS NAÇOES UNIDAS PARA O DESENVOLVIMENTO (PNUD), Informe sobre
Neste sentido, o que se pode constatar é que não se cria equidade por meio apenas da lei e da estrutura institucional do setor saúde. $\dot{E}$ necessário haver um pacto social que fundamente a igualdade básica, embasado em um projeto de retomada do crescimento econômico, que implique em uma methor distribuição da renda $e$ no fortalecimento do setor público; caso contrário, mesmo um sistema voltado para a eqüidade acaba por ser transmutado em algo que termina por replicar a segmentaçäo real e profunda daquela sociedade.

Em resumo, pudemos observar que as propostas de reforma do sistema de proteção social levadas a cabo naqueles dois países, embora partindo de princípios completamente opostos, acabaram tendo um resultado semelhante. Sem querer desconsiderar a importância dos modelos na estruturação das políticas sociais, esta evidência permite considerar que a América Latina esteja atravessando um processo comum de readequação de seus sistemas sociais a uma estrutura social de tal forma segmentada que viabiliza qualquer projeto de aumento da equiidade que não se insira em uma proposta mais abrangente de transformação socioeconômica.

el desarrollo bumano. Santa Fé de Bogotá, Tercer Mundo Editores, 1991.

4. SUNKEL, $O$. Las relaciones centro-periferia y la transnacionalización. Pensamiento Ibero amer. (11), 1987.

5. TOKMAN, V. Pobreza y homogeneización social: tareas para los 90. Pensamiento Iberoamer. (19), 1991.

6. WHITEHEAD, A.N. The concepts and principles of equity and bealth. Copenhagen, World Health Organization, 1990.

7. WORL BANK, World development report. 1993. Washington, 1993.

\begin{abstract}
Four points relating to the iniquities of the health services are brought out. in the first, the economic crisis the region has been going through during recent decades, is discussed and the contention that the tendency to an overall improvement of the living conditions has not been deeply affected by this crisis is questioned. In the second the characteristics of the Latin-American process of development, marked by the deenpeing of iniquities is examined. In the third an analysis of the patterm of social protection in the region is presented and in the last two polar models for the reformation of this pattem are discussed.
\end{abstract}

Health policy. Economic development. Quality of life. Social justice. 